\title{
Modelling a Multi-product, Multi-location and Multi Region based Low Carbon Footprint Supply Chain Configuration Problem for Sanitaryware Manufacturer
}

\author{
Arnav Jain \\ Techture Structures Private Limited \\ Indore, India
}

\author{
Lokik Aggarwal \\ Recventures Education Services \\ Private Limited \\ Delhi, India
}

\author{
Remica Aggarwal \\ School of Business, University of \\ Petroleum \& Energy Studies, \\ Dehradun, India
}

\author{
Lakshay Aggarwal \\ Sociobuddy Technologies Private Limited \\ Delhi, India
}

\begin{abstract}
More and more organizations are realizing the importance of going green and opting for trade with a greener and cleaner environment concern . Present research work explores how carbon emissions concerns could be incorporated and what impact they would have on a supply chain configuration of a sanitaryware manufacturer offering multiple products manufactured at multiple plants and delivered at multiple locations. The given situation therefore depicts a multiobjective supply chain configuration scenario with respect to total carbon costs and/or level of carbon footprints and duration of inbound and outbound shipments.
\end{abstract}

\section{Keywords}

Carbon emissions, carbon emissions cap, sanitaryware manufacturing industry

\section{INTRODUCTION}

Global warming is a concern which is worth a serious consideration. Organizations worldwide are adopting various measures to combat global warming such as opting for renewable sources of energy, redesigning and renovating their products to make themselves more sustainable and environment friendly. Financially as well, low carbon energy efficient technologies offers a wide spectrum of commercial opportunities and it is beneficial as well as reputable for firms to go green and create a different niche for themselves.

Since 1970s, a wide range of literature is available in economics that incorporates environmental concerns through various policy instruments such as imposing a carbon tax or carbon cap over emissions and allowing enterprises to trade by exchanging emission permits among each other. No doubt adopting green technologies is quite expensive and the government policies are really scary specially for new coming enterprises as they are already bound by tight financial budget. Therefore a trade-off is required amongst economic as well as environmental aspects of supply chain.

This paper focuses on such small scale new comer sanitary ware manufacturing enterprise which is catering its range of bathroom fixers and sanitary wares to multiple locations . Sanitaryware manufacturing enterprises are second only in India when it comes to GHG carbon emissions. Rising energy costs and increasingly stringent environmental regulations are therefore driving sanitaryware manufacturers to seek out new solutions to reduce and optimize energy consumption. One classic example is of Riedhammer ${ }^{1}$, a high grade and world leading Indian company that designs and develops EEE and EMS based kilns and dryers for the manufacture of ceramic sanitaryware range which is characterized by significantly reduced carbon dioxide emissions.

There are regular cost budget constraint as well as there are limits on total carbon emissions through a carbon cap and a provision of paying carbon tax in case the emissions are beyond a specified limit. The emissions could be because of the production, logistics and / or storage activities or due to outbound shipments of manufactured goods to the demand centers. A firm often overlook significant sources of emissions that are driven by business practices and operational policies. The prime reason being delivering the product on time and within the budget constraint to its customer firm. Hence, decision about the adequate supply chain configuration for a new sanitary ware manufacturing products introduction is tactical and often quite complex . This research paper tries to provide insights on issues related to product inception with low carbon footprints based supply chain configuration simultaneously. This includes optimizing the multiple objectives of cost and lead time associated with production and delivery of the multiple products subject to the situation which deals with constraints on carbon emissions . Both the cases have been modelled under the effect of long term demand uncertainties. The situation is mathematically formulated as multi-product, multi-location and multi region based low carbon footprint problem.

The research paper is arranged as follows. Section 2 presents the literature review. Section 3 defines the problem. Section 4 presents the basic assumptions, set of decision variables, parameters etc. Section 5 presents the mathematical modelling of the situation presented. Finally, conclusions and managerial implications are presented in section 6 .

\section{LITERATURE REVIEW}

Recent researches has proposes the green supply chain design models by integrating the traditional concepts of supply chain with economic policies for environment . This way they tried to merge the economic aspect with ecological aspect of supply chain [1]-[3]. These green supply chain design models are mostly deterministic in nature and hence have been solved using either goal programming (GP) techniques as in [4]or data envelopment analysis (DEA) approach [5]. Then there are researches which makes use of heuristics and meta heuristics to solve green supply chain design models noteworthy being by [6,7]. There are supply chain models 
which discusses approaches for single as well as multiple existing products [8] or new product development processes ([9], [10]). Green supply chain design models considering the environmental impacts of pipeline inventory, especially in industries with short PLCs with various transportation modes and multiple echelons are discussed in [11]. Similarly, $[12,13,14]$ defies low carbon supply chains and new product introduction concept in various scenarios .

Bazan , Jaber and Zanoni [15] consider a closed loop supply chain model considering issues such as energy used in production processes, carbon emission from production and transportation and number of times a used item can be manufactured . Recently, a mixed-integer non-linear programming model is proposed by [16] which maximizes the total profit subject to constraints such as adjusting the level of pipeline and safety stocks at different supply chain stages, modifying the demand allocations of suppliers in different planning horizons in response to changes in the new product's demand.

\section{PROBLEM DEFINITION}

A sanitary ware manufacturing firm wants to sell its range of products such as bathroom accessories, to various demand centers ( which are construction companies ) in India. The manufacturing firm has plants at different location. The packaging material needs to be delivered at these plants where the product gets manufactured and pack and then deliver to the demand centers of different zones. Decision maker's task is to choose an environmentally conscious low carbon supply chain configuration for the given range of products under uncertain demand scenario and uncertain production plants' capacity scenario which is required to be optimized with regard to environmental impacts obtained over the whole product life cycle.

\section{MODELLING MULTI-PRODUCT, MULTI-LOCATION LOW CARBON FOOTPRINT PROBLEM}

The problems considered here are multiple objective optimization problems which focuses in providing a compromised solution to multiple conflicting objectives of simultaneously minimizing the total costs associated with carbon emissions (taking into account three major costs due to carbon emissions viz. production and packaging costs, storage costs and transportation costs) and the lead time minimization objective. These objectives are subject to constraints such as carbon emissions cap and other operational constraints such as minimum lot size restrictions and upper bounds lot sizes as per supplier's capacity, plants' capacity and carriers' capacity. Then there are demand restrictions as per demand centers' requirements.

\section{DEVELOPMENT OF ISM MODEL \\ 5.1 List of Assumptions}

- Supply chain comprises of supplier, sanitary ware manufacturer with production plants at different locations and demand centres

- Multiple products to be manufacture but belongs to same category

- $\quad$ Supplier capacity is dynamic and known

- $\quad$ There are fixed or certain demand requirements at demand centres

- Carbon emission are generated during the process of procurement, production, storage, and transportation of packaging material and finished goods

- Backorders are not allowed

- No lost sales

- Single mode of transport (Road : Truck / tempo carriers are considered)

- There is a lead time associated with each order made

- No make-to stock policy and hence no pipeline filling requirements

- Demand is satisfied for each product in each period independently

- Supplier's capacity is satisfied for each product independently

- Capacity and demand variables are assumed to have no correlation

- Carbon emission cap is over the entire planning horizon

- Multiple plant (at different locations). The problem becomes location specific

- Market price for carbon is fixed ( for the case of carbon cap and trade )

- Carrier loading capacity is same for all products

\subsection{List of Indices}

$i=1$ : packaging component

$i=k$ where $k=k_{1}, k_{2}, \ldots . K$ finished products

$p$ : designates manufacturing plant $; p=1,2, \ldots P$

$t$ : time period ; $t=1,2, \ldots T$

$c$ : designates the carrier used in the road transport $; c=1,2 \ldots C$

\subsection{List of Parameters}

$\operatorname{Pr}_{1 t c}^{p}$ : Per unit cost of procuring the packaging component in time period ' $t$ ' through $c$ th carrier

$\operatorname{Pr}_{i r c t}^{p}$ : Per unit cost of producing the component ' $i$ ' ( $\forall i \in$ $k=k 1, k 2, \ldots K)$ in time period ' $t$ '

$S t_{1 r c t}^{p}$ : Per unit storage cost of packaging component at $p^{\text {th }}$ plant in time period ' $t$ '

$S t_{i r c t}^{p}$ : Per unit storage cost of ' $i$ 'th finished product component $(\forall i \in k=k 1, k 2, \ldots K)$ to be delivered from ' $p$, th plant to $r^{\text {th }}$ demand region in " $t$ th time period through " $c$, th mode of transport

$\operatorname{Tr}_{1 c t}^{p}:$ Per unit transportation cost

$\operatorname{Tr}_{1 c t}^{p}$ : Per unit transportation cost of packaging component to be transported to $p^{\text {th }}$ plant from $c^{\text {th }}$ carrier in time period ' $t$ '

$T r_{i r c t}^{p}$ : Per unit transportation cost of shipping $i^{\text {th }}$ finished product unit $(\forall i \in k=k 1, k 2, \ldots K)$ to $r^{\text {th }}$ demand region in time period ' $t$ '

$C E_{1 c t}^{1 p}$ : Amount of carbon emissions caused in procuring one unit of packaging component to the manufacturing plant ' $p$ ' 
$C E_{\text {irct }}^{2 p}$ : Amount of carbon emissions caused in producing one unit of finished product ' $i(\forall i \in k=k 1, k 2, \ldots K)$ by the manufacturing plant ' $p$ '

$C E_{1 c t}^{3 p}$ : Amount of carbon emissions caused in storing one unit of packaging product component at the warehouse

$C E_{\text {irct }}^{4 p}$ : Amount of carbon emissions caused in storing one unit of $i^{\text {th }}$ product component $(\forall i \in k=k 1, k 2, \ldots K)$ at the warehouse

$C E_{1 c t}^{5 p}$ : Amount of carbon emissions caused in transporting one unit of packaging component from the place of supplier to the manufacturing plant

$C E_{\text {irct }}^{6 p}$ : Amount of carbon emissions caused in transporting one unit of ' $i$ 'th product component $(\forall i \in k=k 1, k 2, \ldots K)$ from the production plant to the ' $r$ th demand centre through $c^{\text {th }}$ carrier

$C e_{Q}$ : Total carbon emission quota for the entire planning horizon

$D_{i r c}^{t}$ : Demand for $i^{\text {th }}$ product component $(\forall i \in k=$ $k 1, k 2, \ldots K)$ in $r^{\text {th }}$ demand region in time period ' $t$ '

$I_{\text {irtc }}^{p}$ : Defines the inventory of $i^{\text {th }} \quad$ product $\quad(\forall i \in k=$ $k 1, k 2, \ldots K)$ carried to $r^{\text {th }}$ demand centre from the period ' $t$ ' to ' $t+1$ '

$P S c_{1 c t}^{p}$ : Packaging supplier's capacity for packaging component in time period ' $t$ '

$C L c_{1 c t}^{p}:$ ' $c$ th carrier's loading capacity for packaging product component to be supplied to plant ' $p$ ' in time period ' $t$ '

$C L c_{i r c t}^{p}:$ ' $c^{\text {th }}$ carrier's loading capacity for loading $i^{\text {th }}$ product component

$(\forall i \in k=k 1, k 2, \ldots K)$ to be supplied to $r^{\text {th }}$ demand region from plant ' $p$ ' in time period ' $t$ '

$P L c_{i r c t}^{p}$ : Production/manufacturing plant ' $p$ ' capacity for $i^{\text {th }}$ product component

$(\forall i \in k=k 1, k 2, \ldots K)$ to be supplied to $r^{\text {th }}$ demand region in time period ' $t$ '

$L S_{1 c}^{p}$ : Min lot size for packaging component in time period ' $t$ ' for plant ' $p$ ' to be transported through carrier ' $c$ '

$L S_{i c}^{p}$ : Min lot size for ' ${ }^{\prime}$ 'th finished product component $(\forall i \in k=k 1, k 2, \ldots K)$ to be transported in $r^{\text {th }}$ demand region in time period ' $t$ ' from plant ' $p$ ' through carrier ' $c$ '

$L T_{i r c t}^{p}$ : Lead time of $i^{\text {th }}$ product component to be transported through ' $c$ th carrier from production plant ' $p$ ' to ' $r$ 'th demand centre in time period ' $t$ '

$\mu_{L T}^{p} \underset{\text { irct }}{p}$ : Mean lead time of $i^{\text {th }}$ product component $(\forall i \in k=$ $k 1, k 2, \ldots K)$ transported through ' $c$ th carrier from production plant ' $p$ ' to ' $r$ th demand region in time period ' $t$ '

\subsection{List of decision variables}

$X_{\text {irtc }}^{p}$ : Amount of $i^{\text {th }}(\forall i \in k=k 1, k 2, \ldots K)$ product transported from plant ' $p$ ' to $r^{\text {th }}$ demand region in time period ' $t$ ' through carrier ' $c$ '

$X_{i t c}^{p}$ : Amount of $i^{\text {th }}$ packaging product transported from supplier to plant ' $p$ ' in time period ' $t$ ' through carrier ' $c$ '
$B_{\text {irct }}^{p}$ : binary variable which takes value 1 if $k^{\text {th }}$ product transported from manufacturing plant ' $p$ ' to the demand region ' $r$ ' in time period ' $t$ ' through carrier ' $c$ ', 0 otherwise

$B_{i t c}^{p}$ : binary variable which takes value 1 if packaged component is transported to plant ' $p$ ' from supplier through carrier ' $c$ ' in time period ' $t$ ', 0 otherwise

\section{MODEL FORMULATION: SINGLE FIRM, STRICT CARBON EMISSION CAP}

In this situation, we are considering that the enterprise who is to manufacture a range of products over its manufacturing plants in different locations must adhere to a fixed cap on emissions over the entire planning horizon. The problem is solved taking each cost (i.e. procurement cost, production cost , storage costs as well as transportation cost). The problem faced by the firm can now be written as follows:

$$
\begin{aligned}
& \operatorname{Min} Z_{1}=\sum_{p \in P} \sum_{c \in C} \sum_{t \in T} \operatorname{Pr}_{1 c t}^{p} X_{1 c t}^{p}+\sum_{p \in P} \sum_{i \in k=1, \ldots K} \sum_{r \in R} \sum_{c \in C} \sum_{t \in T} \operatorname{Pr}_{i r c t}^{p} X_{i r c t}^{p} \\
&+\sum_{p \in P} \sum_{i=1}^{p} \sum_{c \in C} \sum_{t \in T} S t_{1 c t}^{p} X_{1 c t}^{p}+ \\
&+\sum_{p \in P} \sum_{i \in k=1,2, . . K} \sum_{r \in R} \sum_{c \in C} \sum_{t \in T} S t_{i r c t}^{p} X_{i r c t}^{p} \\
&+\sum_{p \in P} \sum_{i=1} \sum_{c \in C} \sum_{t \in T} T C_{1 c t}^{p} X_{1 c t}^{p}+ \\
& \sum_{p \in P} \sum_{i \in k=1,2, . . K} \sum_{r \in R} \sum_{c \in C} \sum_{t \in T} T C_{i r c t}^{p} X_{i r c t}^{p}
\end{aligned}
$$

$\operatorname{Min} Z_{2}=\sum_{p \in P} \sum_{i \in k=1,2, . . K} \sum_{r \in R} \sum_{c \in C} \sum_{t \in T} L T_{i r c t}^{p} X_{i r c t}^{p}$

Subject to

$$
\begin{aligned}
& I_{i r c t-1}^{p}+\sum_{c \epsilon C} X_{i r c t}^{p}-I_{i r c t}^{p}=D_{i r}^{t} \quad, \forall p \in P, \forall i \in k= \\
& k 1, k 2, \ldots K, \forall t \epsilon T, r \in R \\
& \sum_{c \epsilon C} X_{1 c t}^{p} \leq P S c_{1 c t}^{p} \quad \forall p= \\
& P, \forall t \epsilon T \\
& \sum_{c \epsilon C} X_{i r c t}^{p} \leq P L c_{i r c t}^{p} \\
& k 1, \ldots K, \quad \forall t \epsilon T, \quad \forall r \in R \\
& 0 \leq X_{1 c t}^{p} \leq C L c_{1 c t}^{p} \quad \forall p=P, \forall t \epsilon T, \forall c \epsilon C \\
& 0 \leq \sum_{c \in C} X_{i r c t}^{p} \leq C L c_{i r c t}^{p} \quad \forall p=P, \forall i \in k= \\
& k 1, \ldots K, \quad \forall t \epsilon T, c \epsilon C, \quad \forall r \in R \\
& \sum_{c \epsilon C} X_{1 c t} B_{1 c t} \geq Q_{t}^{\prime} \quad \forall t \in T \\
& \quad \sum_{i \in k=1,2, . . K} \sum_{c \epsilon C} X_{i r c t}^{p} B_{i r c t} \geq Q_{t}^{\prime \prime} \\
& \quad=P, \forall t \in T, \forall r \in R
\end{aligned}
$$




$$
\begin{aligned}
& \sum_{p \in P} \sum_{c \in C} \sum_{t \in T} C E_{1 c t}^{1 p} P r_{1 c t}^{p} X_{1 c t}^{p} \\
& +\sum_{p \in P} \sum_{i \in k=1, \ldots K} \sum_{r \in R} \sum_{c \in C} \sum_{t \in T} C E_{i r c t}^{2 p} P r_{i r c t}^{p} X_{i r c t}^{p} \\
& +\sum_{p \in P} \sum_{i=1} \sum_{c \in C} \sum_{t \in T} C E_{1 c t}^{3 p} S t_{1 c t}^{p} X_{1 c t}^{p} \\
& +\sum_{p \in P} \sum_{i \in k=1,2, . . K} \sum_{r \in R} \sum_{c \in C} \sum_{t \in T} C E_{i r c t}^{4 p} S t_{i r c t}^{p} X_{k i r c t}^{p} \\
& +\sum_{p \in P} \sum_{c \in C} \sum_{t \in T} C E_{1 c t}^{5 p} T C_{1 c t}^{p} X_{1 c t}^{p}+ \\
& \sum_{p \in P} \sum_{i \in k=1,2, . . K} \sum_{r \in R} \sum_{c \in C} \sum_{t \in T} C E_{i r c t}^{6 p} T C_{i r c t}^{p} X_{i r c t}^{p} \leq C e_{Q}
\end{aligned}
$$

$B_{\text {irtc }}^{p} \in[0,1] \quad \forall i=k \in k 1, k 2, \ldots, K, \forall t \in T, c \in C(11)$

$B_{1 t c}^{p} \in[0,1] \quad, \forall t \in T, c \in C$

$X_{\text {irtc }}^{p} \geq 0 \forall i \in k=k 1, k 2, \ldots K$,

$\forall t \in T, c \in C$

$X_{1 c t}^{p} \geq 0, \quad \forall t \in T, c \epsilon C$

Equation (1) minimizes multiple cost objectives contributing to total costs which includes the procurement and production cost, storage costs and transportation costs . Equation (2) defines the lead time objective function represented by objective function . Equation (3) defines the net inventory balancing equation for demand. Inequality (4) represents the packaging supplier's capacity on order quantity for every period. Inequality (5) defines the constraint of production plant capacity over the sum total of units transported from all the carriers to different regions over the time planning horizon. Constraint represented by inequality (6) represents supplier capacity constraint on overall quantity i.e. total amount / quantity transported through all carriers is less than equal to supplier capacity. Inequality represented by (7) represents the lot size restrictions for packaging component whereas inequality (8) corresponds to lot size constraints for finished product. Carbon emission constraint is given by inequality (9) . Equation (11)-(12) represents the binary nature of variable and whereas inequality (13) - (14) represents the non-negativity of decision variables .

\section{MANAGERIAL IMPLICATIONS AND FUTURE DIRECTIONS}

1. When it comes to including eco-management aspects of eco-efficiency and carbon footprints by industries such as sanitaryware industries, curbing harmful emissions during the various processes of manufacturing, storage and delivery have to operate in the tight schedule considering a lot many other aspects. In such case, the proposed models could be of use to the manager to aware him about the extra over and above investments he can make in the form of tax / penalty . in the case, the organisation is not earning a high turnover in terms of profits, it is usually not advisable to spend extra because of increased carbon emissions .

2. The managerial considerations have now days also shifted to socio-ecologic or socio -economic beneficial supply chains . The practical development and generalisation may show the need to include other environmental sustainability measures such as water usage, hazardous solid waste and /or particulate emissions as well as the influencing factors such as environmental and regulatory issues, traffic and driving behaviours.

3. Problem could be solved through the standard mathematical programming techniques such as Goal programming ( Pre-emptive or Non - Preemptive ) [17] as well as metaheuristics and application of Bioinspired evolutionary algorithms such as NSGA , GA etc. $[18,19]$

\section{REFERENCES}

[1] Kleindorfer, P.R., Singhal, K. and Van Wassenhove, L.N.(2005), "Sustainable operations management," Production \& Operations Management, Vol. 14, No. 4, pp. 482-492. [1]

[2] Linton, J.D., Klassen, R., and Jayaraman, J.2007. Sustainable supply chains: An introduction. Journal of Operations Management, 25( 6) , 1078-1082.[2]

[3] Benjaafar, S., Li, Y. Daskin, M. 2013. Carbon footprint and Management of Supply Chains: Insights from Simple Models. IEEE Transactions on Automation Science and Engineering, 10(1) . [3]

[4] Pati, R. K., Vrat, P. and Kumar, P. 2008. A Goal Programming Model for Paper RecyclingSystem. Omega, 36, 405-417. [4]

[5] Neto, J.Q.F, Ruwaard , J.A.B., Nunen , E.E.V., Hoek , E.V. 2008. Designing and evaluating sustainable logistics networks", International Journal of Production Economics. 111, 195-208. [5]

[6] Validi , S., Bhattacharya, A. and Byrne, P.J. 2014a. A Case Analysis of a Sustainable Food Supply Chain Distribution System - A Multi-Objective Approach. International Journal of Production Economics , 152, 7187. [6]

[7] Validi, S., Bhattacharya, A. and Byrne, P.J. 2014b. Integrated Low- carbon Distribution System for the demand side of a product Distribution supply chain: A doe -guided Mopso Optimiser based solution Approach.International Journal of Production Research , 52(10),3074-3096. [7]

[8] Melo, M. T., Nickel, S. and Saldanha-da-Gama, F. 2009. Facility Location and Supply Chain Management $-\mathrm{A}$ Review.European Journal of Operational Research , 196, 401-412. [8]

[9] Blackhurst , J., Wu, T. and P.O. Grady , P.O. 2010. PCDM: A Decision support modelling methodology for supply chain, Products and Process Design Decisions. Journal of Operations Management , 23, 325-343. [9]

[10] Arikan, E., Fichtinger, J. and Ries, J.M. (2013), “Impact of Transportation Lead-time Variability on the Economic and Environmental Performance of Inventory Systems" International Journal of Production Economics. doi:10.1016/j.ijpe.2013.06.005.[10]

[11] Gan, T.S., and Grunow, M.(2013), "Concurrent Product Supply Chain Design: A Conceptual Framework \& Literature Review", Proceedia CIRP , Vol. 7, pp 9196.[11]

[12] Brandenburg, M. and Schiling, R. 2012. Value impacts of dynamics and uncertainty in tactical supply chain design for new product Introduction", Business Informatics, Decision Theory and Practice, edited by M. 
Geiger, J. Geldermann and S. Vob , 23-46, Aachen :Shaker.[12]

[13] Brandenburg, M. , Kuhn , H. , Schiling, R. and Seuring, S. 2014 b. Performance and value oriented decision support for supply chain configuration. Logistics Research, 7(1),doi:10.1007/s12159-014-0118-8.[13]

[14] Brandenburg, M. 2015. Low Carbon Supply Chain Configuration for a New Product - A Goal Programming Approach.International Journal of Production Research, $53 \quad$ (21), 6588-6610, $: 10.1080 / 00207543.2015 .1005761 .[14]$

[15] Bazan, E., Jaber, M.Y. \& Zanoni, S. 2017. "Carbon emissions and energy effects on a two-level manufacturer-retailer closed-loop supply chain model with remanufacturing subject to different coordination mechanisms," International Journal of Production Economics, Elsevier, 183(PB), 394-408.[15]

[16] Negahban, A.\& Dehghanimohammadabadi, M.2018. "Optimizing the supply chain configuration and production-sales policies for new products over multiple planning horizons," International Journal of Production Economics, Elsevier, 196(C), 150-162.[16]

[17] Aggarwal ， R. , Singh S.P. and Kapur P.K.2018. Integrated Dynamic Vendor Selection Problem Considering Time Varying Stochastic Data , Benchmarking: An International Journal ,25(3), 21-23, Emerald Publishing .

[18] Aggarwal , R and Bakshi, A. 2015.Chance Constraint based supplier selection using NSGAII" , Procedia Computer Science, Elsevier Science Direct , 48(1), 699 705 .

[19] Aggarwal R., Bakshi A. 2014. Non Dominated Sorting Genetic Algorithm for Chance Constrained Supplier Selection Model with Volume Discounts. In: Nguyen N.T., Attachoo B., Trawiński B., Somboonviwat K. (eds) Asian Conference on Intelligent Information and Database Systems (ACIIDS) , Lecture Notes in Computer Science, LNCS Springer, 8398 (1) , 465-474. 